\title{
Effect of Graphene Oxide Precursor Loading on the Surface of Melamine-Formaldehyde/rGO Sponge with Enhanced Ultra-Hydrophobicity for Oils Removal
}

\author{
Natcha Jirasuttisarn ${ }^{1}$, Chaval Sriwong ${ }^{1,2, *}$ \\ ${ }^{1}$ Department of Chemistry, Faculty of Science, King Mongkut's Institute of Technology Ladkrabang, Bangkok, Thailand \\ ${ }^{2}$ Smart Materials Research and Innovation Unit, Faculty of Science, King Mongkut's Institute of Technology Ladkrabang, Bangkok, \\ Thailand
}

\author{
Email address: \\ chaval.sr@kmitl.ac.th (C. Sriwong) \\ ${ }^{*}$ Corresponding author
}

\section{To cite this article:}

Natcha Jirasuttisarn, Chaval Sriwong. Effect of Graphene Oxide Precursor Loading on the Surface of Melamine-Formaldehyde/rGO Sponge with Enhanced Ultra-Hydrophobicity for Oils Removal. American Journal of Nano Research and Applications. Vol. 8, No. 2, 2020 , pp. $22-27$. doi: $10.11648 /$ j.nano.20200802.12

Received: April 21, 2020; Accepted: May 6, 2020; Published: May 14, 2020

\begin{abstract}
This work presented a facile, green and effective method to prepare the ultra-hydrophobic melamine-formaldehyde (MF) sponge loaded with reduced graphene oxide (rGO) by a conventional heating method using the various contents of graphene oxide, $\mathrm{GO}(1,3,5,10$ and $15 \mathrm{mg})$ precursor, and vitamin $\mathrm{C}$ as a reducing agent. These $\mathrm{GO}$ precursors were used to increase the roughness of the MF/rGO sponge surfaces. Then GO precursor, $\mathrm{rGO}$, pristine MF sponge and as-prepared MF/rGO sponge samples were confirmed and characterized by Fourier transform infrared spectroscopy (FTIR), Raman spectroscopy, scanning electron microscopy (SEM), transmission electron microscopy (TEM) and water contact angle techniques. Moreover, the adsorption capacity, oils removal performance and recyclability of MF/rGO sponges were also investigated. The results showed that the water contact angle values were increased from $131^{\circ}$ to $144.1^{\circ}$ upon the increasing of GO precursor loading. The highest water contact angle $\left(144.1^{\circ}\right)$ exhibited the ultra-hydrophobic property by the sponge prepared using GO loading as $10 \mathrm{mg}$ $\left(\mathrm{MF} / \mathrm{rGO}-10 \mathrm{mg}\right.$ ). The adsorption capacity $\left(Q_{e}\right)$ of the MF/rGO-10 mg sponge was higher than $102{\mathrm{~g} . \mathrm{g}^{-1}}^{-1}$ for all the oils removal tested (palm oil, gasoline, diesel and lubricant oil), and had the highest value was about $112 \mathrm{~g} \cdot \mathrm{g}^{-1}$ for lubricant oil. Besides, $\mathrm{MF} / \mathrm{rGO}$ sponge can be well-recycled use up to 10 times for all oils removal. Therefore, this study provides a new alternative method to prepare the MF sponge loaded with $\mathrm{rGO}(\mathrm{MF} / \mathrm{rGO})$, which can be used and reused for the cleanup of oil spillages from water.
\end{abstract}

Keywords: Graphene Oxide (GO), Reduced Graphene Oxide (rGO), Melamine-Formaldehyde (MF) Sponge, Vitamin C, Ultra-Hydrophobicity, Oil Spills

\section{Introduction}

With the increase of industrial development, the leaking of oils, crude oil and petroleum products has resulted in serious environmental and ecological damages [1-2]. Hence, the problem of oil/water separation has incentive attention and had become a big challenge. As a result, a variety of adsorber materials that can effective adsorb, remove and transfer spilled oils contaminants from water are urgently needed to help preserve the environmental pollutions [3-4].

In recent years, a several synthetic polymer sponges, such as, polyurethane (PU), polystyrene (PS), polypropylene (PP), melamine and melamine-formaldehyde (MF), have been widely utilized to cleanup of oil spills due to their low operational costs, lightweight, good flexibility, easy to use and ready availability $[2,4-5]$. However, these polymers are suffered from the low oil adsorption capacity, poor selectivity and low chemical stability in an organic solvents media [5-6]. To solve these problems, the modifications of the polymer sponges are to be needed [7-9].

Recently, reduced graphene oxide (rGO), a single-atom thick with a two-dimensional (2D) carbon nanomaterial, has 
attracted a great interest due to its unique large surface area, excellent hydrophobicity, thermal and chemical stability, good flexibility and very lightweight [9-10]. In general, rGO can be synthesized from graphene oxide (GO) using both thermal and chemical reduction processes, but the later has some drawbacks in the case of use a several toxic reductants, for example, hydrazine $\left(\mathrm{N}_{2} \mathrm{H}_{4}\right)$ and sodium borohydride $\left(\mathrm{NaBH}_{4}\right)$ [11-12].

In this work, the preparation of melamine-formaldehyde (MF) sponge loaded with reduced graphene oxide (rGO) through a conventional heating method using the various contents of graphene oxide (GO) precursor loading was reported. While vitamin $\mathrm{C}$ or ascorbic acid was used as a reducing agent owing to its natural chemical, green, non-toxicity and availability. Then, GO precursor, rGO, pristine MF sponge and as-prepared MF/rGO sponge samples were confirmed and characterized by FTIR, Raman, SEM, TEM and water contact angle techniques. Moreover, the adsorption capacity, oils removal performance and recyclability of $\mathrm{MF} / \mathrm{rGO}$ sponges were also investigated.

\section{Materials and Methods}

\subsection{Chemicals and Materials}

Melamine-formaldehyde (MF) sponge was purchased from Scotch Brite, 3M Co., Ltd, Thailand. Graphite powder (99\%) and L-ascorbic acid (vitamin $\mathrm{C},\left(\mathrm{C}_{6} \mathrm{H}_{8} \mathrm{O}_{6}\right) 99 \%$ ) were obtained from Sigma-Aldrich (USA). Sulfuric acid $\left(\mathrm{H}_{2} \mathrm{SO}_{4}, 98 \%\right)$ and potassium permanganate $\left(\mathrm{KMnO}_{4}\right)$ were purchased from Merck (Germany). Ethanol $\left(\mathrm{C}_{2} \mathrm{H}_{5} \mathrm{OH}, 95 \%\right)$ was obtained from Baker (USA). All chemicals were used as received without further purification.

\subsection{Preparation of Melamine-Formaldehyde/rGO (MF/rGO) Sponge}

\subsubsection{Synthesis of GO Precursor and rGO Samples}

Graphite oxide was synthesized by a modified Hummers method [13]. Then synthesized graphite oxide powder was redispersed in distilled water under sonication for $2 \mathrm{~h}$, and followed by centrifuging. After that, the aqueous suspension of GO precursor $(5 \mathrm{mg} / \mathrm{mL})$ was obtained. Finally, rGO sample was easily synthesized according to previous paper [14] by a conventional heating method at $90{ }^{\circ} \mathrm{C}$ for 30 min using GO and vitamin $\mathrm{C}$ as precursor and reductant, respectively.

\subsubsection{Preparation of $M F / r G O$ Sponge}

A commercially available MF sponge was cut into $2 \times 2 \times$ $1 \mathrm{~cm}^{3}$ cubes and cleaned by distilled water and ethanol for 30 min and dried at $60{ }^{\circ} \mathrm{C}$ in an oven. Then, MF sponge was immersed into $50 \mathrm{~mL}$ of distilled water and followed by adding of vitamin $\mathrm{C}$ solution to adjust the $\mathrm{pH}$ of distilled water as 3 . After that, $1 \mathrm{mg}$ of GO precursor was added and stirred for $5 \mathrm{~min}$, followed by heating at $90{ }^{\circ} \mathrm{C}$ for $30 \mathrm{~min}$ under slow stirring. Then $\mathrm{MF} / \mathrm{rGO}$ sponge was taken out, washed with distilled water and ethanol several times to remove all impurities. After dried in oven at $60^{\circ} \mathrm{C}$ for $3 \mathrm{~h}$, the MF/rGO-1 sponge was obtained. The samples with different GO loading, such as, 3, 5, 10 and $15 \mathrm{mg}$ were prepared as described above, and were named as MF/rGO-3 $\mathrm{MF} / \mathrm{rGO}-5, \mathrm{MF} / \mathrm{rGO}-10$ and $\mathrm{MF} / \mathrm{rGO}-15$, respectively.

\subsection{Characterizations}

The functional groups of GO and rGO samples were studied through a Fourier-transformed infrared spectroscopy (FT-IR) (Nicolet iS50, Thermo Fisher Scientific Inc., USA). The chemical structure of the samples were also well-confirmed by Raman spectroscopy technique (DXR Smart, Thermo Fisher Scientific Inc., USA). The microstructures of the samples were examined by scanning electron microscopy (SEM, JEOL-JSM5800LV, Japan) and transmission electron microscopy (TEM, JEJOL-JM-2010, Japan). Water contact angle measurements were performed by a contact angle analyzer by using the volume of water droplet as $5 \mathrm{uL}$.

\subsection{Measurements of Oils Adsorption Capacity}

The MF/rGO sponge was dipped into various oils (palm oil, gasoline, diesel and lubricant oil) for $3 \mathrm{~min}$. The adsorption capacity $Q_{e}(\mathrm{~g} / \mathrm{g})$ was calculated according to Equation (1),

$$
Q_{e}=\left(m_{t}-m_{i}\right) / m_{i}
$$

where $m_{i}$ and $m_{t}$ are the weight (g) of the sponge sample before and after adsorption, respectively [10, 15-16].

\subsection{Recyclability}

The recyclability of the $\mathrm{MF} / \mathrm{rGO}-10 \mathrm{mg}$ sponge sample was evaluated by repeated adsorption-squeezing processes. The adsorption-squeezing was carried out by immersing the sponge into palm oil, gasoline, diesel and lubricant oil, until the sponge became saturation, then manually squeezing the sponge to extract adsorbed oils, repeating 10 times to test the recyclable utilization performance of the sponge sample.

\section{Results and Discussion}

\subsection{Synthesis of MF/rGO Sponge}

Figure 1 shows the photographs of pristine MF sponge and as-prepared MF/rGO sponge samples. To the naked eyes,

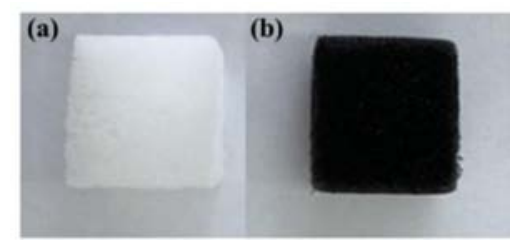

Figure 1. Physical appearances of (a) MF sponge and (b) MF/rGO sponge.

it can be clearly seen that, the surface of $\mathrm{MF} / \mathrm{rGO}$ sponge has the black in color (see in Figure 1(b)); on the other hand, the pristine MF sponge has the white color (see in Figure 1(a)). This result indicates the blackness color of the MF/rGO has impregnated or covered with $\mathrm{rGO}$ sheet particles on the 
sponge surface $[5,10]$. In this work, vitamin $\mathrm{C}$ not only used as a reducing agent, but also act as a surface modification of MF sponge with the positive charge of $\mathrm{H}^{+}$on the surface of the sponge. Thus, GO nanosheets could be successfully adhered to the skeleton of MF surface through the electrostatic interaction between the positive charge on the surface of MF sponge and the negative charge on the natural skeleton of GO nanosheets [17]. After the reduction process, rGO nanosheets was produced from GO precursor, and still maintained cover and impregnation on the surface of $\mathrm{MF} / \mathrm{rGO}$ sponge samples.

\subsection{Raman and FTIR Analysis of GO Precursor and rGO}

Figure 2 displays the Raman and FTIR spectra of GO precursor and rGO samples. It can be observed that the characteristic peaks of GO and rGO exhibited two broad peaks at around $1350 \mathrm{~cm}^{-1}$ and $1600 \mathrm{~cm}^{-1}$ (see in Figure 2(a)), which are confirmed to disordered carbon (D band) and graphitic $\mathrm{sp}^{2}$ carbon ( $\mathrm{G}$ band), respectively $[4,6,18]$. Remarked that, the $\mathrm{I}_{\mathrm{D}} / \mathrm{I}_{\mathrm{G}}$ intensity ratio of $\mathrm{rGO}$ increases compared to that of $\mathrm{GO}$, which attributes to the formation of large amounts of $\mathrm{sp}^{2}$ carbon domains with smaller the average size after the reduction of GO $[5,8,12]$. The FTIR spectra of GO precursor and rGO samples are also shown in Figure 2(b). After the reaction of GO precursor, the absorption bands of some the oxygen-functional groups, such as, hydroxyl (-OH), carbonyl
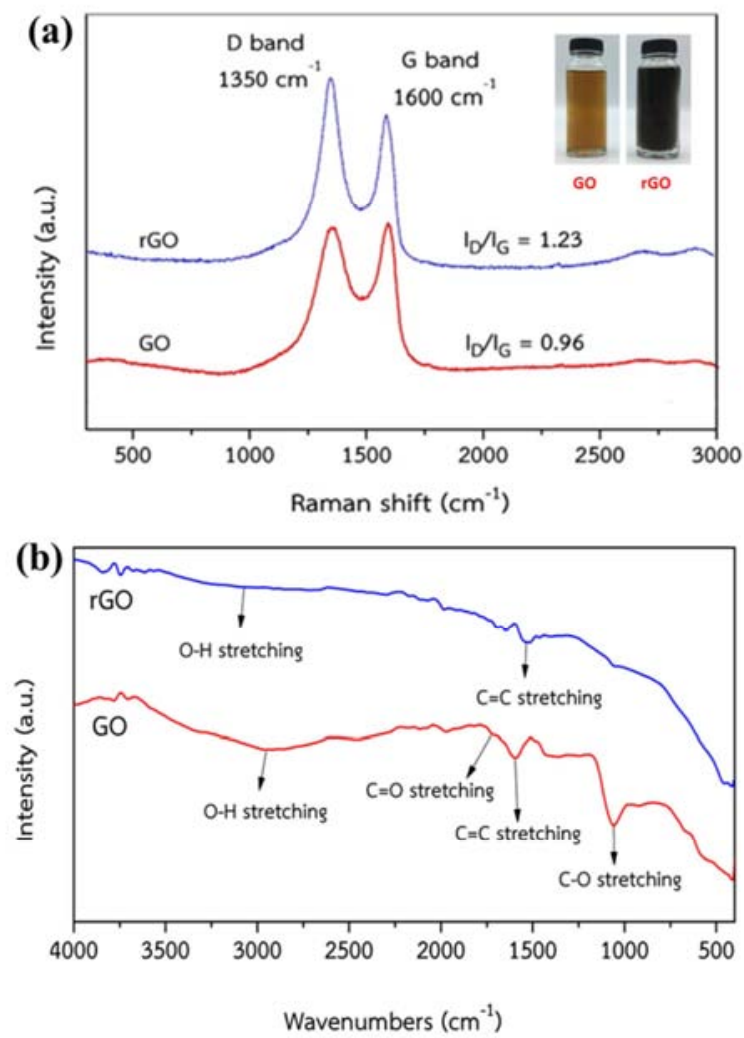

Figure 2. (a) Raman and (b) FTIR spectra of graphene oxide (GO) precursor and reduced graphene oxide (rGO) samples.

$(-\mathrm{C}=\mathrm{O})$ and epoxy $(-\mathrm{C}-\mathrm{O})$ were mostly removed $[6,9]$. This result indicated that the $\mathrm{GO}$ precursor was produced to $\mathrm{rGO}$ over the reduction method. In addition, this reduction was also easily confirmed from the color change of $\mathrm{GO}$ and $\mathrm{rGO}$ suspensions (from a brown to black in color, as displayed in inset of Figure 2(a)) [10, 12].

\subsection{SEM and TEM Analysis of rGO}

Figure 3 shows the SEM and TEM images of rGO sample. As can be found from Figure 3(a), the morphology of rGO particles had a flake-like structure with very small sizes and high aggregation. This result agreement with the TEM image in Figure 3(b), rGO particles had very thin sheets.

\subsection{SEM Characterization of MF/rGO Sponges}

Figure 4 illustrates the surface morphology of the pristine $\mathrm{MF}$ and as-prepared $\mathrm{MF} / \mathrm{rGO}$ sponges with various contents of GO precursor loading. It can be obviously seen that all the MF sponges had a three-dimensional highly micro-porous structure with uniform pore size. The skeleton template of pristine MF sponge has a very smooth surface (see in Figure 4(a), whereas the MF/rGO sponge samples showed the rough surface with impregnated and covered from rGO sheet particles on the skeleton of the sponges (see in Figure 4(b) (f)). The roughness of the sponge surfaces were increased along with the increasing of GO precursor loading. Form the SEM images of the sponge prepared using GO precursor as 10 $\mathrm{mg}(\mathrm{MF} / \mathrm{rGO}-10 \mathrm{mg})$, it has mostly covered and well-impregnated with $\mathrm{rGO}$ nanosheets on the skeleton surface (see in Figure 4(e)). However, the sample prepared with $15 \mathrm{mg}(\mathrm{MF} / \mathrm{rGO}-15 \mathrm{mg})$ of GO precursor showed more stack and aggregates of rGO sheet particles (see in Figure 4(f)). This may be due to the high and excess content of GO loading, thus it easy to self-assembly of rGO sheet particles.

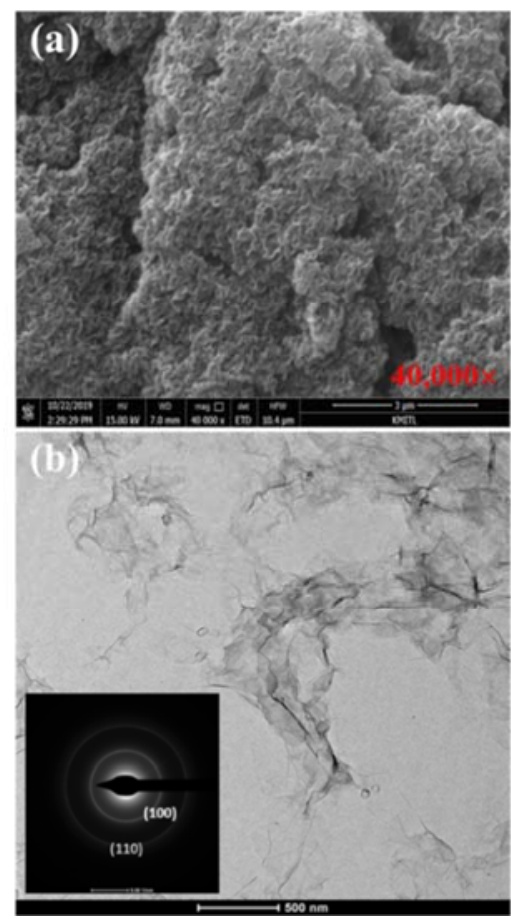

Figure 3. (a) SEM and (b) TEM images of $r G O$ sample. 


\subsection{Raman Analysis of MF/rGO Sponges}

Figure 5 displays the Raman spectra of rGO and all $\mathrm{MF} / \mathrm{rGO}$ sponges. In the Figure 5, two obvious bands at around $1350 \mathrm{~cm}^{-1}$ (D band) and $1600 \mathrm{~cm}^{-1}$ (G band) of rGO can be clearly observed with all the MF/rGO sponge samples. Noted that the intensities of both two bands of $\mathrm{MF} / \mathrm{rGO}$ samples were increased upon the increasing of GO loading. This result well-confirmed the increase of rGO particles had covered and impregnated on the surface of MF/rGO sponges.
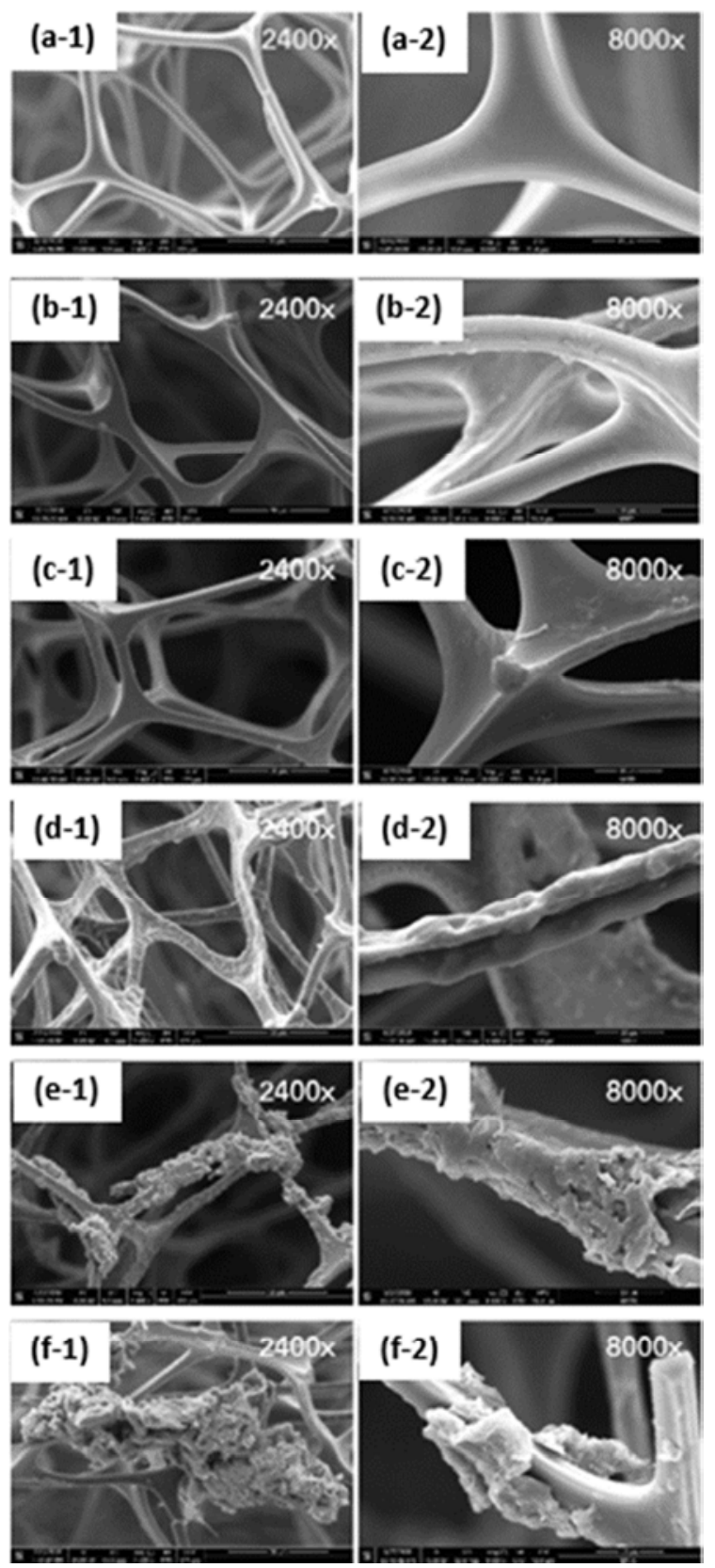

Figure 4. SEM images of (a) MF sponge and MF/rGO sponges with various contents of GO precursor loading; (b) $1 \mathrm{mg}$, (c) $3 \mathrm{mg}$, (d) $5 \mathrm{mg}$, (e) $10 \mathrm{mg}$ and (f) $15 \mathrm{mg}$.

\subsection{Water Contact Angle Values of MF/rGO Sponges}

To understand the hydrophobic properties of all sponge samples, the water contact angle measurements were carried out, as the results are shown in Figure 6. It can be seen that the water contact angle values of $\mathrm{MF} / \mathrm{rGO}$ sponges increased from $131^{\circ}$ to $144.1^{\circ}$ along with the increasing of GO loading, except the MF/rGO-15 mg. The highest water contact angle $\left(144.1^{\circ}\right)$ exhibited as the ultra-hydrophobic property by the sponge prepared using GO loading of $10 \mathrm{mg}$ (MF/rGO-10 mg). These results were directly related to the content of rGO sheets

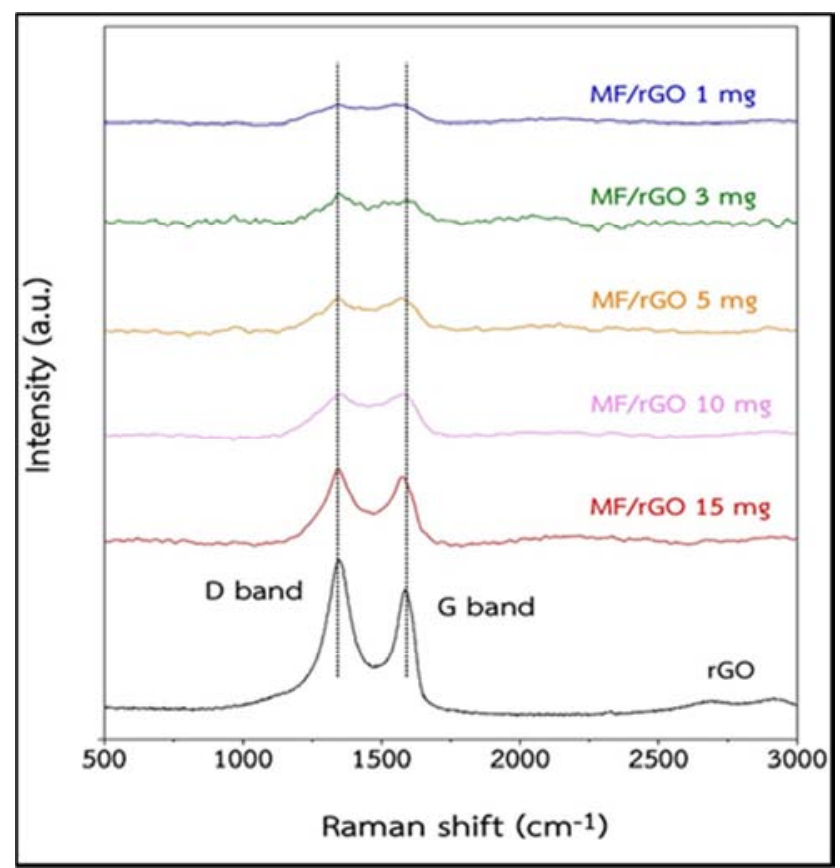

Figure 5. Raman spectra of pristine $r G O$ and $M F / r G O$ sponges samples with various contents of $G O$ precursor loading.

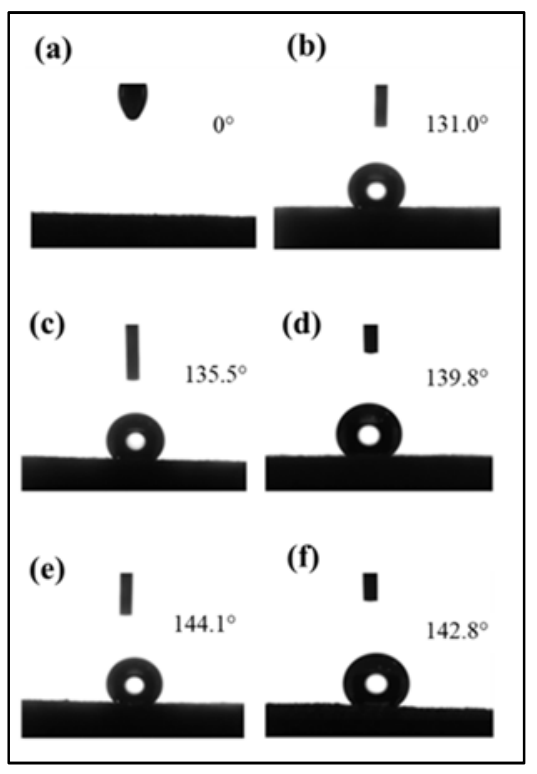

Figure 6. Photographs of water contact angle values of (a) MF sponge and $M F / r G O$ sponges with various contents of GO precursor loading; (b) $1 \mathrm{mg}$, (c) $3 \mathrm{mg}$, (d) $5 \mathrm{mg}$, (e) $10 \mathrm{mg}$ and (f) $15 \mathrm{mg}$.

which existed, covered and impregnated on the surface of the $\mathrm{MF} / \mathrm{rGO}$ sponges. These results are corresponded to the results from SEM and Raman techniques. As a result, it can be 
concluded that the highest water contact angle of MF/rGO-10 mg sponge accompanied with the ultra-hydrophobic behavior, resulting the best oil adsorption ability.

\subsection{Oil Adsorption Performance of MF/rGO Sponge}

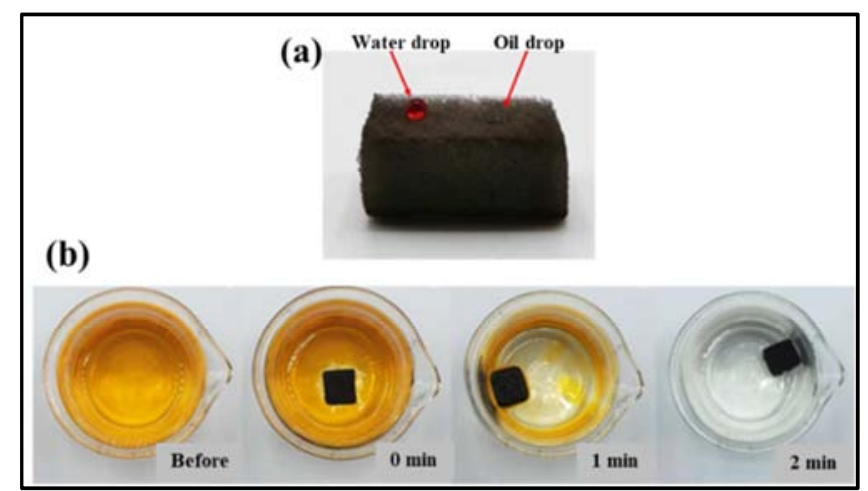

Figure 7. Photographs of (a) water and oil droplets supported on MF/rGO sponge and (b) adsorption of palm oil from water with $M F / r G O$ sponge..

The oil-water separation experiment was tested using the as-prepared $\mathrm{MF} / \mathrm{rGO}-10 \mathrm{mg}$ sponge. The hydrophobicity of the sponge was determined by placing palm oil and water droplets on the surface of MF/rGO sponge, as shown in Figure 7(a). It can be seen that the water droplet in spherical shape was still maintained on the surface of the as-prepared $\mathrm{MF} / \mathrm{rGO}$ sponge; in contrast, the oil droplet was immediately adsorbed into the sponge and disappeared. Furthermore, the removal performance of palm oil from water was also studied. As can be seen in the Figure 7(b), when the MF/rGO sponge contacted with the oil on the water, the palm oil was quickly adsorbed into the sponge within a few minutes [10, 12], and the adsorbed oil can be easily gathered by the squeezing process. These results pointed out that the prepared MF/rGO sponge had high adsorption ability for oil removal from water.

\subsection{Recyclability of MF/rGO Sponge}

The reusability of adsorbents is very important for practical applications. In this study, the MF/rGO-10 mg sponge was tested by repeated adsorption-squeezing processes. Figure 8 shows the adsorption capacity and recyclability (up to 10 times) of as-prepared MF/rGO-10 mg sponge for absorbing palm oil, gasoline, diesel and lubricant oil. From the first use, the $\mathrm{MF} / \mathrm{rGO}$ sponge exhibited the highest adsorption capacity $\left(Q_{e}\right)$ values were about 102 g.g ${ }^{-1}, 107.5$ g.g ${ }^{-1}, 110.5$ g.g ${ }^{-1}$ and 112 g.g-1 for gasoline, diesel, palm oil and lubricant oil, respectively. This because of the adsorption performance of the sponge or foam is dependent on the polarity and density of various oils [19-20]. After 10 cycles, although the adsorption capacity values of the $\mathrm{MF} / \mathrm{rGO}$ sponge were

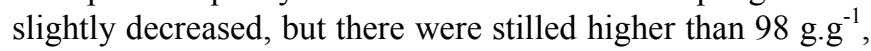
for all the oils removal test. This indicates that the as-prepared $\mathrm{MF} / \mathrm{rGO}$ sponge remained high the adsorption capacity and stability for removing oils form water. Thus, the $\mathrm{MF} / \mathrm{rGO}$ sponge expected to a great potential in the treatment of large oily spillage from water.

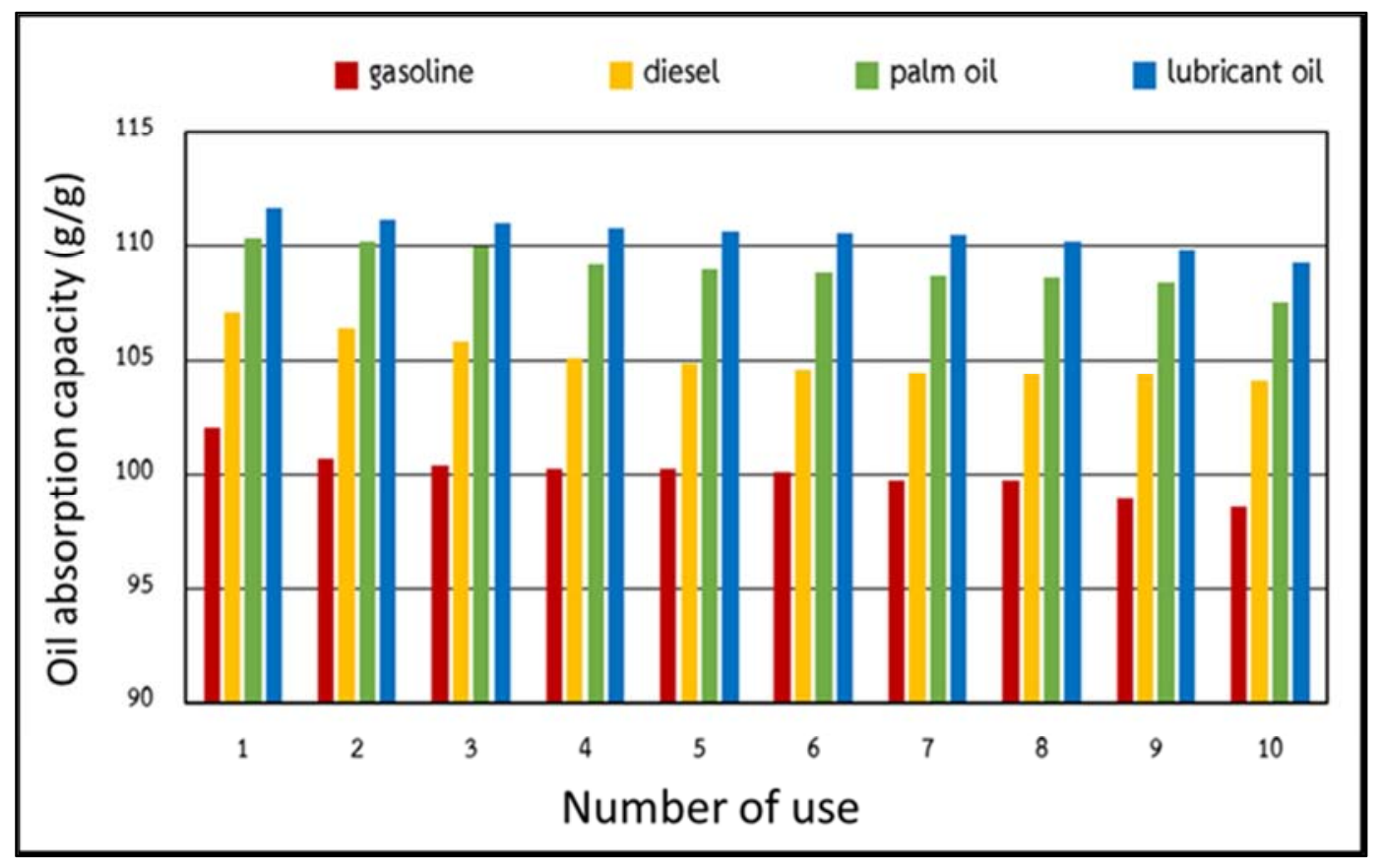

Figure 8. Adsorption capacity $\left(Q_{e}\right)$ and recyclability of as-prepared MF/rGO-10 $\mathrm{mg}$ sponge for absorbing palm oil, gasoline, diesel and lubricant oil, respectively.

\section{Conclusions}

In summary, MF/rGO sponges were successfully prepared by a conventional heating method using the various contents of GO precursor loading, and vitamin $\mathrm{C}$ as a reducing agent. The characterizations of all the samples were well-confirmed and analyzed by Raman, FTIR, SEM and TEM techniques. Depending on the appropriate contents of GO loading, the 
as-prepared $\mathrm{MF} / \mathrm{rGO}$ sponges exhibited the excellent oil adsorption ability. The highest water contact angle of $\mathrm{MF} / \mathrm{rGO}-10 \mathrm{mg}$ sponge showed as the ultra-hydrophobic property. Moreover, the adsorption capacity $\left(Q_{e}\right)$ of the $\mathrm{MF} / \mathrm{rGO}-10 \mathrm{mg}$ sponge was higher than $102{\mathrm{~g} . \mathrm{g}^{-1}}$ for all the oils removal tested, and had the highest value was about 112 g. $\mathrm{g}^{-1}$ for lubricant oil. Besides, MF/rGO-10 mg sponge can be well-recycled use up to 10 times for all oils removal from water.

\section{Acknowledgements}

The authors would like to thanks the Department of Chemistry, Faculty of Science, King Mongkut's Institute of Technology Ladkrabang (KMITL) for the financial support.

\section{References}

[1] J. Wang, and G. Geng (2015) "Highly recyclable superhydrophobic sponge suitable for the selective sorption of high viscosity oil from water", Marine Pollution Bulletin. 57: 118-124.

[2] Y. Lu, Y. Wang, L. Liu, and W. Yuan (2017) "Environmental-friendly and magnetic/silanized ethyl cellulose sponges as effective and recyclable oil-absorption materials", Carbohydrate Polymers. 173: 422-430.

[3] T. Xu, Z. Wang, Y. Ding, W. Xu, W, Wu, Z. Zhu, and H. Fong (2018) "Untralight electrospun cellulose sponge with super-high capacity on absorption of organic compounds", Carbohydrate Polymers. 179: 164-172.

[4] S. Yang, L. Chen, L. Mu, and P-Cheng Ma (2014) "Magnetic graphene foam for efficient adsorption of oil and organic solvents", Journal of Colloid and Interface Science. 430: 337-344.

[5] A. P. Periasamy, W. P. Wu, R. Ravindranath, P. Roy, G. L. Lin, and H. T. Chang (2017) "Polymer/reduced graphene oxide functionalized sponges as superabsorbents for oil removal and recovery", Marine Pollution Bulletin. 114: 888-895.

[6] X. Lu, Z. Cui, W. Wei, J. Jiang, J. Huang, and J. Liu (2016) "Constructing polyurethane sponge modified with silica/graphene oxide nanohybrids as a ternary sorbent", Chemical Engineering Journal. 284: 478-486.

[7] C. Liu, J. Yang, Y. Tang, L. Yin, H. Tang, and C. Li (2015) "Versatile fabrication of the magnetic polymer-based graphene foam and application for oil-water separation", Colloids and Surface A: Physicochemical and Engineering Aspects. 468: $10-16$.

[8] M. Peng, G. Chen, G. Zeng, A. Chen, K. He, Z. Huang, L. Hu, J Shi, L. Yuan, and T. Huang (2018) "Superhydrophobic kaolinite modified graphene oxide-melamine sponge with excellent properties for oil-water separation", Applied Clay Science. 163: 63-71.
[9] Z. Rahmani, M. T. Samadi, A. Kazemi, and A. M. Rashidi (2017) "Nanoporous graphene and graphene oxide-coated polyurethane sponge as a highly efficient, Superhydrophobic, and reusable oil spill absorbent", Journal of Environmental Chemical and Engineering. 5: 5025-5032.

[10] Y. He, Y. Liu, T. Wu, J. Ma, X. Wang, Q. Gong, W. Kong, F. Xing, Y. Liu and J. Gao (2013) "An environmentally friendly method for the fabrication of reduced graphene oxide foam with a super oil absorption capacity", Journal of Hazardous Materials. 260: 796-805.

[11] T. Guo, X. Chen, L. Su, C. Li, X. Huang, and X. Z. Tang (2019) "Stretched graphene nanosheets formed the obstacle walls in melamine sponge toward effective electromagnetic interference shielding applications", Materials and Design. 182: 108029 .

[12] C. Zhang, H. Li, Z. Zhuo, R. Dugnan, C. Sun, Y. Chen, and H. Liu (2017) "Facile fabrication of ultra-light and higly resilient PU/RGO foams for microwave absorption", RSC Advances. 7: 4132 .

[13] C. Phompet, C. Sriwong, and C. Ruttanapun (2019) "Mechanical, dielectric, thermal and antibacterial properties of reduced graphene oxide (rGO)-nanosized $\mathrm{C}_{3} \mathrm{AH}_{6}$ cement nanocomposites for smart cement-based materials", Composites Part B. 175: 107128.

[14] C. Sriwong, K. Choojun, and S. Kongtaweelert (2017) "Investigation of the influences of reaction temperature and time on the chemical reduction of graphene oxide by conventional method using vitamin $\mathrm{C}$ as a reducing agent", Materials Science Forum. 909: 225-230.

[15] S. Gupta, W. D. He, and N. H. Tai (2016) "A comparative study on superhydrophobic sponges and their application as fluid channel for continuous separation of oils and organic solvents from water", Composites Part B. 99-106.

[16] L. Dashairya, A. Sahu, and P. Saha (2019) "Stearic acid treated polypyrrole-encapsulated melamine formaldehyde superhydrophobic sponge for oil recovery", Advanced Composites and Hybrid Materials. 2: 70-82.

[17] D. Li, M. B. Muller, S. Gilje, R. B. Kaner, and G. G. Wallace (2008) "Process able aqueous dispresions of graphene nanosheets", Nature Nanotechnology. 3: 101-105.

[18] Y. Liu, J. Ma, T. Wu, X. Wang, G. Huang, Y. Liu, H. Qiu, Y. Li, and W. Wang (2013) "Cost-effective reduced graphene Oxide-coated polyurethane sponge as a highly efficient and reusable oil-absorbent", ACS Applied Materials \& Interfaces. 5: 10018-10026.

[19] L. Qiu, R. Zhang, Y. Zhang, C. Li, Q. Zhang, and Y. Zhou (2018) "Superhydrophobic, mechanically flexible and recyclable reduced graphene oxide wrapped sponge for highly efficient oil/water separation", Frontiers of Chemical Science and Engineering. 12: 390-399.

[20] N. Yousefi, K. Wong, Z. Hosseinidoust, H. O. Sørensen, and N. Tufenkji (2018) "Hierarchically porous, ultra-strong reduced graphene oxide-cellulose nanocrystal sponges for exceptional adsorption of water contaminants", Nanoscale. 10: 7171-7184. 